\title{
$7(1467)$
}

Rejurenescence without encystment and without nuclear fusion in Uroleptus?

\section{By Gary N. Calkins.}

\section{[From the Department of Zoölogy, Columbia University.]}

Experiments made during the last two years on Uroleptus mobilis have shown that renewal of vitality follows conjugation, both parents, coming from the same protoplasm and all kept under identical conditions of food and environment. It was also shown that asexual reorganization occurring during encystment, likewise results in rejuvenescence.

It was argued that, since the only Mommon phenomenon in conjugation and encystment is the nuclear dissolution and absorption in the protoplasm, the renewal of vitality after each is due to the chemical and physical changes in the protoplasm set up by the addition of relatively large quantities of nucleoproteins added to it. To test this working hypothesis the following experiments were undertaken last April and May. Individuals of the same ancestry ( $P$ series) in the I40th generation, were allowed to conjugate; a normal ex-conjugant was isolated (V series), and this, with the parent $\mathrm{P}$ series, were maintained as controls, the latter to show the degree of vitality without conjugation, the former to show the effect of conjugation. Other pairs of conjugating individuals were isolated in a minute drop of culture medium, a pair at a time, and cut with a scalpel across the angle of the $\mathrm{V}$ made by the two individuals in conjugation. The detached angle of the $\mathrm{V}$ and one of the arms of the $\mathrm{V}$ were immediately fixed and stained to determine the stage of conjugation at the time of cutting. The other part was isolated in culture medium and set aside for observation. Seven pairs were successfully cut in this way, and in the desired plane; four of these died within Io days, three continued to live forming the $\mathrm{X}$ series, the $\mathrm{X} 6$ series, and the $\mathrm{X}_{7}$ series.

The period required for reorganiztion of the normal individual after conjugation and prior to the first cell division, varies from 
3 to 6 days and the process may be watched in the living cell in which the changes of the nucleus are clearly visible. The individual forming the $\mathrm{V}$ series required seven days for this reorganization.

It was most unexpected and interesting to find that the cut individuals invariably went through the same nuclear reorganization states as those of a normal ex-conjugant. If they died, death was always at the last phase of the reorganization process. The individuals destined to live and form the $\mathrm{X}$ series, the $\mathrm{X} 6$ series, and the $\mathrm{X}_{7}$ series, required eight, nine, and eight days respectively before the first division of the young cells. From the start each series represented by five different lines, was carried on in culture like any normal ex-conjugant series, with similar records of the daily division rate, the average rate for ten days, and the average rate for the first and second sixty day periods. The results for the four months following the operations are given in the following table.

Average Division Rates in io-Day Periods, of Controls and Experimental SERIES.

\begin{tabular}{|c|c|c|c|c|c|c|c|c|c|c|c|}
\hline & & & $\begin{array}{c}\text { Parent } \\
\text { P Series } \\
\text { Non- } \\
\text { conju- } \\
\text { gant. }\end{array}$ & $\begin{array}{l}\text { Filial } \\
\text { V Series } \\
\text { Ex-con- } \\
\text { jugant. }\end{array}$ & $\begin{array}{l}\text { X Series } \\
\text { Cut } \\
\text { Conju- } \\
\text { gating. }\end{array}$ & $\begin{array}{l}\text { V Series } \\
\text { Control } \\
\text { Ex-con. } \\
\text { jugant. }\end{array}$ & $\mid \begin{array}{c}\text { P Series } \\
\text { Control } \\
\text { Non- } \\
\text { conju- } \\
\text { gant. }\end{array}$ & $\begin{array}{c}\text { X } 6 \\
\text { Series } \\
\text { Cut } \\
\text { Conju- } \\
\text { gating. }\end{array}$ & $\begin{array}{c}\mathbf{X}, 7 \\
\text { Series } \\
\text { Cut } \\
\text { Conju- } \\
\text { gating. }\end{array}$ & $\begin{array}{l}\text { V Series } \\
\text { Control } \\
\text { Ex-con- } \\
\text { jugant. }\end{array}$ & $\begin{array}{l}\text { P Series } \\
\text { Control } \\
\text { Non- } \\
\text { conju- } \\
\text { gant. }\end{array}$ \\
\hline \multirow{9}{*}{$\begin{array}{l}\text { Ist } \\
\text { 2d } \\
3 \mathrm{~d} \\
4 \text { th } \\
5 \text { th } \\
\text { 6th } \\
\text { Ist } \\
\text { 2d } \\
\text { Aver }\end{array}$} & & “ & 13.6 & I3.8 & 8.8 & I 3.8 & 13.2 & 15.8 & I 7.6 & 18.2 & I2.4 \\
\hline & & ". & 12.8 & 16.0 & 9.4 & 14.6 & 10.0 & 13.3 & 16.4 & 16.8 & 12.2 \\
\hline & & “ & 13.2 & I3.8 & I3.4 & I 8.2 & I 2.4 & 15.8 & 18.6 & I8.2 & 16.8 \\
\hline & “ & “ & 10.0 & I 4.6 & 13.4 & I6.8 & I 2.2 & 14.0 & 15.8 & 14.8 & 13.2 \\
\hline & “ & “ & 12.4 & 18.2 & 14.2 & I 8.2 & 16.8 & 13.2 & I 5.4 & 17.0 & 16.4 \\
\hline & “ & “ & 12.2 & I6.8 & 12.0 & 14.8 & 13.2 & I 4.0 & I6.8 & I6.6 & I 4.4 \\
\hline & 60 & “. & 12.4 & I 5.5 & II. 9 & r6.0 & I 2.9 & 14.3 & 16.8 & I6.9 & 14.2 \\
\hline & 60 & “ & 14.2 & 16.3 & 12.5 & I 4.8 & I I. 5 & 10.3 & 12.0 & 12.9 & 7.7 \\
\hline & $\begin{array}{l}\text { rage } \\
\text { days }\end{array}$ & $\begin{array}{l}\text { I } 20 \\
\text { s. }\end{array}$ & 13.3 & 15.9 & 12.2 & 15.4 & 12.2 & 12.3 & 14.4 & 14.9 & 10.9 \\
\hline
\end{tabular}

It has been shown in an earlier paper ${ }^{1}$ that the extent of rejuvenescence as indicated by the division rate, varies with the age of the parent series at the time of conjugation. The greater the vitality of the parent series the less is the difference in vitality between parent and filial series. For example, if the filial series starts by a conjugation occurring during the first 60 days (ap-

'Calkins, "Uroleptus mobilis. II. The Renewal of Vitality through Conjugation." Jour. Exper. Zoöl., Vol. 29, No. 1, 1919. 
proximately 100 generations) the average difference in vitality amounts to only I.5 divisions in ro days for the first 60-day period of the offspring. If the filial generation starts from a parent series which is 130 to 200 generations old, the difference in vitality between parent and offspring increases to between 3 and 4 divisions in Io days, and if the filial generation starts from a parent series that is about 300 generations old, the difference in vitality rises to a maximum of 17 or more divisions in Io days.

In the present experiments the parent $P$ series was in the I40th generation when the filial $V$ series was started, and in the r6oth generation when $\mathrm{X} 6$ and $X_{7}$ were cut. The difference in vitality between the $\mathrm{V}$ series and the $\mathrm{P}$ series, 3.I divisions in Io days for the first 60 days, agrees with the results obtained with all ex-conjugants started at corresponding periods of the parent cycle, and shows the normal rejuvenating effects of conjugation.

The cut conjugants show different results in regard to renewal of vitality. The $\mathrm{X}$ series shows no rejuvenescence at all but agrees with the non-conjugant $P$ series throughout. The X6 series agrees with the non-conjugant $P$ series in the first 60-day period but has a higher average division rate for the second $60-$ day period, while its average for four months is intermediate between the non-conjugant $\mathrm{P}$ series and the ex-conjugant $\mathrm{V}$ series. The $\mathrm{X}_{7}$ series, on the other hand, shows for the entire period the same vitality as the ex-conjugant $\mathrm{V}$ series and gives the same evidence of rejuvenescence.

These three divergent cases are difficult to interpret. Each recovered perfectly after the operation; each underwent reorganization processes apparently identical with those of normal ex-conjugants; each gave rise to a population similar to that of a normal ex-conjugant except that in none of them have I seen a case of encystment; epidemics of conjugation have been frequent in each of these populations.

A possible explanation may be found in the fact that the conjugating pairs which were operated upon to give the $X, X 6$, and $\mathrm{X}_{7}$ series were cut at different phases of the process of conjugation. In none of them had nuclear interchange taken place. One pair was cut at the very outset of conjugation; this gave rise to the $\mathrm{X}$ series which showed no rejuvenescence. Another pair was cut 
at the stage of the first maturation spindles; this gave rise to the $\mathrm{X} 6$ series with evidence of partial rejuvenescence. The third pair was cut at the stage of the second maturation division and this gave rise to the $\mathrm{X}_{7}$ series which showed the same rejuvenescence as the normal ex-conjugant from the same source.

Many more experiments of the same nature are now under way and must be carried out before conclusions can be drawn. These three cases indicate, however, that the absorption of nucleo-proteins in the cytoplasm and which occurred in all cases, is not, by itself at least, the secret of renewed vitality.

\section{$8(1468)$}

The total carbonate content of the arterial and venous plasma in normal individuals.

By R. W. Scotr (by invitation).

[From the Department of Medicine, School of Medicine, Western Reserve University, Cleveland.]

In the course of some observations on the respiratory disturbances seen in certain diseased conditions it became necessary for the sake of comparison to determine the total carbon dioxide of the arterial and venous plasma in individuals with normal cardio-respiratory mechanisms. In all the bloods of nineteen normal individuals at rest have been examined. In each case samples of arterial and venous blood were obtained within a few minutes of each other.

Method.-The arterial blood was obtained by direct puncture of the radial artery using a technique similar to that employed by Stadie. ${ }^{1}$ The venous blood was collected without stasis from one of the large veins at the bend of the elbow. To avoid contact with air both samples were carefully delivered under albolene into paraffin coated centrifuge tubes and immediately centrifuged at high speed. One c.c. of the separated plasma was delivered under carbonate free ammonia water contained in a receiving cup

${ }^{1}$ Stadie, W. C., J. Exp. Med., 1919, XXX, 215. 